\section{Evaluation of the Patterns of Mortality Due to Acute Poi- soning in Imam Reza Hospital, Mashhad, Iran, 2016}

\section{Fares Najari ${ }^{1 *}$, Bita Dadpour ${ }^{2}$, Ideh Baradaran Kayal ${ }^{1}$ and Marzieh Khalilzadeh ${ }^{1}$ \\ ${ }^{1}$ Department of Forensic Medicine and Toxicology, Shahid Beheshti Uni- versity of Medical Sciences, Tehran, Iran}

${ }^{2}$ Medical Toxicology Research Center, School of Medicine, Mashhad University of Medical Sciences, Mashhad, Iran

\section{Abstract}

\section{Background:}

Acute poisoning is among the most common causes of referring to the emergency departments worldwide. Since the pattern of poisoning regarding the type of component and symptoms might vary in different regions of Iran, the current study aimed at identifying the most commonly used poisoning materials causing death in Mashhad, Khorasan Razavi Province, Iran.

\section{Methodology}

The current cross sectional, retrospective study was conducted on all patients died from poisoning, including intentional, accidental, occupational, and criminal cases, at Imam Reza Hospital, Mashhad, Iran, in 2016. Data of patients who died from poisoning were collected from clinical records as well as forensic records including cause of death, autopsy findings, and the results of toxicological tests. Data were analyzed with SPSS version 22 using the Chi-square.

\section{Results}

Total mortality due to poisoning in the specific poisoning ward of Imam Reza Hospital was 71 cases in 2016, 14 cases had exclusion criteria, out of which the records of 55 cases were available. Among the 55 enrolled cases, $16(29 \%)$ were female and $39(71 \%)$ were male. The mean age of deceased patients was $49.84 \pm 20.28$ years (15-88), with the peak mortality of 45 to 60 years. Among the cases died of poisoning, 22 cases $(40 \%)$ were admitted for the intentional

*Corresponding author: Fares Najari, Department of Forensic Medicine and Toxicology, Shahid Beheshti University of Medical Sciences, Tehran, Iran, Tel: +98 2122227021; E-mail: najari.hospital@sbmu.ac.ir

Citation: Najari F, Dadpour B, Kayal IB, Khalilzadeh M (2017) Evaluation of the Patterns of mortality due to acute Poisoning in Imam Reza Hospital, Mashhad Iran, 2016. J Toxicol Cur Res 1: 001.

Received: August 10, 2017; Accepted: October 9, 2017; Published: October 23, 2017

Copyright: @ 2017 Najari F, et al. This is an open-access article distributed under the terms of the Creative Commons Attribution License, which permits unrestricted use, distribution, and reproduction in any medium, provided the original author and source are credited. self-poisoning and 33 cases $(60 \%)$ for unintentional poisoning. According to autopsy evaluations $(n=32)$, the opium poisoning was the main cause of death $(40.6 \%, n=13)$.

\section{Discussion and conclusion}

According to the results of the current study, most of the poisoning deaths were, unintentional (unlike previous studies) and opium consumption was the main cause of death from poisoning.

Keywords: Death; Forensic; Opium; Poisoning

\section{Introduction}

Every year, many people are poisoned due to accidental, intentional, drug abuse and occupational exposure reasons and refer to the emergency medical care centers all around the world. The intentional consumption of medicines is one of the health problems in Asia-Pacific regions, in such an extended manner that about 300,000 poisoning deaths are reported in this area annually [1,2].

The pharmaceutical products most frequently implicated in poisoning are those which are most frequently prescribed and are consequently in the home, and most common route is oral [3].

Acute intentional poisoning is among the main causes of referring to the emergency departments worldwide; in addition, it is one of the main causes of death, growing every year. Identification of the poisoning patterns is helpful in finding the risk factors and early diagnosis. According to the results of a study by Moghadamnia from 1997 to 2000 in Mazandaran, Iran, about 51\%, and according to that of Shadnia et al., (2003) in Tehran, Iran about $79 \%$ of poisoned patients were the intentional self-poisoning by medicines and chemical compounds [4,5].

In many countries, about $30 \%$ of poisoning cases occur in young people within the age range of 20 to 30 years [4-7]. In a study by Afzali et al., in Hamadan, Iran from 2005 to 2007, the mean age of the poisoned patients were 40.5 years and the peak mortality reported within the age range of 21 to 30 years; intentional poisoning with $52.2 \%$ had the highest rate [8]. In a study by Torkashvand et al., [9] in Rafsanjan, Iran, the mean age of the patients died from poisoning was $23.10 \pm 15.16$ years with the peak age range of 11 to 30 years and $58.1 \%$ of the cases were the intentional self-poisoning [9].

In the developed countries, the intentional self-poisoning mostly occurs by medicines with lower toxicity, while in the developing countries people usually attempt self-poisonings by pesticides that are highly toxic and are associated with a high mortality $[7,10]$. In addition, death from poisoning is the top leading cause of death after infectious diseases [11-12].

Since the type of poisoning material and the symptoms vary in different regions of Iran, the current study aimed at identifying the most common poisoning materials causing death and pattern of mortality due to acute poisoning in Mashhad, Iran.

\section{Methodology}

The current descriptive, cross sectional study was conducted on all 
patients died from poisoning at Imam Reza Hospital the only referral hospital of poisoning in Mashhad, Khorasan Razavi, Iran, at 2016. Exclusion criteria were underlying disease in past medical history, co ingestion, unknown toxicity. Out of 7732 cases who referred to the poisoning ward of Imam Reza Hospital and admitted due to acute poisoning, 71 deceased included in study and among them seven cases were exclude because of unknown toxicity, five cases because of co-ingestion and 2 cases because of underlying disease. Two cases were excluded from the study due to incomplete information. At last 55 cases enrolled in study. Authors provided a list of patients who referred to the hospital and admitted in the poisoning ward in 2016, after obtaining the necessary permissions from the hospital and Mashhad Forensic authorities. The cases died of poisoning in the study year were listed and their demographic and medical information including age, gender, poisoning agent, marital status, type of poisoning, and chief complaint were extracted and recorded in a researcher-designed checklist. All of 55 deceased were referred to Mashhad Legal Medicine Organization (LMO), among them 32 cadavers autopsied and post-mortem qualitative toxicology tests were performed for 27 cases. The forensic records including mode and cause of death, autopsy findings, and the results of post-mortem qualitative toxicology tests were collected by a physician who worked at the forensic organization.

The collected data were analyzed with SPSS version 22 using the Chi-square. $\mathrm{P}$ value $<0.05$ was considered significant.

\section{Results}

Out of 7732 patients with acute poisoning, 71 deceased included in study, 14 cases had exclusion criteria, out of which the records of 55 cases were available. Among the 55 enrolled cases, 16 (29\%) were female and $39(71 \%)$ male and most of them (34 cases) were married. The mean age of the study population was $49.84 \pm 20.28$ years; ranged from 15 to 88 , with the peak age range of 45 to 60 years. The common poisoning material was opium with the frequency of $50.9 \%$ (28 cases), followed by aluminum phosphide known as rice tablet ( 7 cases), amphetamine (6 cases), sedative (4 cases), alcohol ( 4 cases), zinc phosphide (3 cases), acetaminophen ( 2 cases), organophosphate compound (1 case)

Among the cases died of poisoning, 22 cases (40\%) were admitted for the intentional self-poisoning and 33 cases $(60 \%)$ for unintentional poisoning. The most common chief complaint at the admission was lack of consciousness with $69.1 \%$ frequency ( 38 cases) followed by nausea and vomiting (9 cases) (Table 1). According to certificate of death, heart failure and respiratory failure with $61.8 \%$ and $32.7 \%$, respectively, were the most modes of death from poisoning (Table 2). According to interpretations by forensics, most of the death cases (40.6\%) attributed to opioid consumption (Table 3). No significant relationship was observed between the gender and accidental or intentional poisoning in the death cases $(\mathrm{P}=0.115)$. According to the results of forensic qualitative toxicology evaluations, morphine and methadone with $53.1 \%$ frequency were the most common consumed materials (Table 4). 32 cadavers autopsied which 22 cases had pulmonary pathology that pulmonary edema and pulmonary congestion was most common pathology in lungs (22 cases), other pathologies in lung were; pulmonary hemorrhage ( 7 cases), purulent discharge in respiratory tract ( 7 cases), overinflated lung ( 3 cases), pleural adhesion to lung ( 5 cases), and pleural effusion ( 1 case). Most of these pulmonary pathology was found in opium overdosed deceased patients. Among cadavers autopsied heart pathology was found in 11 cases, liver pathology in 2 cases, and brain pathology in 2 cases. The most common pathology in heart was atherosclerosis and found often in opium overdose.

\begin{tabular}{|c|c|c|}
\hline Clinical Symptom & Frequency, N & Percentage \\
\hline Reduced consciousness & 38 & 69.1 \\
\hline Nausea and vomiting & 9 & 16.4 \\
\hline Abdominal pain & 3 & 5.5 \\
\hline Seizure & 2 & 3.6 \\
\hline Headache & 1 & 1.8 \\
\hline Restlessness & 1 & 1.8 \\
\hline Visual impairment & 1 & 1.8 \\
\hline Total & 55 & 100 \\
\hline
\end{tabular}

Table 1: The frequency of chief complaint to evaluate the poisoning death pattern in Imam Reza Hospital, Mashhad, 2016.

\begin{tabular}{|c|c|c|}
\hline Mode of Death & Frequency & Percentage \\
\hline Heart failure & 34 & 61.8 \\
\hline Respiratory failure & 18 & 32.7 \\
\hline Gastrointestinal bleeding & 1 & 1.8 \\
\hline Cancer & 1 & 1.8 \\
\hline Severe acidosis & 1 & 1.8 \\
\hline Total & 55 & 100 \\
\hline
\end{tabular}

Table 2: Modes of death based on the certificate of death issued by LMO to evaluate the poisoning death pattern in Imam Reza Hospital, Mashhad, 2016.

\begin{tabular}{|c|c|c|}
\hline Autopsy Result & Frequency & Percentage \\
\hline Death due to opioids consumption & 13 & 40.6 \\
\hline Death due to poisoning with medicines & 8 & 25 \\
\hline Death due Impairment in vital organs following poisoning & 5 & 15.6 \\
\hline Death due injury caused by medicine use & 5 & 15.6 \\
\hline Death due to methanol consumption & 1 & 3.1 \\
\hline Total & 32 & 100 \\
\hline
\end{tabular}

Table 3: The frequency of autopsy results to evaluate the poisoning death pattern in Imam Reza Hospital, Mashhad, 2016.

\begin{tabular}{|c|c|c|}
\hline Toxicology Result & Frequency & Percentage \\
\hline Positive methadone + morphine & 17 & 53.1 \\
\hline Negative results & 5 & 5.6 \\
\hline Not tested & 5 & 5.6 \\
\hline Methadone & 2 & 6.3 \\
\hline Aluminum phosphide & 1 & 3.1 \\
\hline Methanol & 1 & 3.1 \\
\hline Acetaminophen & 1 & 3.1 \\
\hline Total & 32 & 100 \\
\hline
\end{tabular}

Table 4: The qualitative toxicology test results conducted in the Forensic laboratory, Mashhad Office, to evaluate the poisoning death pattern in Imam Reza Hospital, Mashhad, 2016.

\section{Discussion}

According to the results of the current study, in-hospital fatality 
rate due to poisoning was $0.92 \%$; like study by Afshari et al., from 1993 to 2000 in Imam Reza hospital, Mashhad which poisoning death rate was $0.6 \%[13]$ but it was $1.3 \%$ and $3.8 \%$ in the studies by Shadnia et al. [5], and Afzali et al. [8], respectively. In the current study most of the poisoned patients were unintentional, while it was reported as intentional self-poisoning in the studies by Afzali et al. [8], Shadnia et al. [5], Afshari et al. [13], and Vatandoost et al. from 2000 to 2001 in Tehran, Iran, [6] as well as the studies conducted in Turkey [14] and India from 1999 to 2002 [15]. This difference may be related to that; most of mention studies performed on all population of poisoning patient not only deceased (unlike our study). Results of the current study showed that the majority of fatal poisoning cases were male that was consistent with those of Afzali et al., and Torkashvand et al. [8,9]; the reason can be explained by more challenges with socioeconomic dilemmas and easier access to opioids and toxins in males. Results of the current study showed that the peak mortality from poisoning occurred in the age range of 45 to 60 years, however; the studies by Torkashvand et al. [9], Afzali et al. [8], Shadnia et al. [5], and Vatandoost et al. [6]. Reported the age range of 21 to 30 years as the peak mortality due to poisoning.

Most of the current study cases referred to the hospital due to low consciousness that was similar to the study by Afzali et al., and Vatandoost et al. [6,8]. Opium consumption was the main cause of death from poisoning in the current study; similar results were reported by Afzali et al. [8], and Shadnia et al. [5], as well as the research conducted in England and Wales [16]. Nevertheless, poisoning with organ chlorine constituted the majority of poisoned patients in Bangladesh [17]; however, it was the consumption of tricycle antidepressants and cardiovascular medicines in a study in Germany from 1996 to 2003 [18]. Since there is limited access to opioids in the developed countries, higher prevalence of poisoning by medicines is expected, and due to poor control over the distribution of chemical toxins in the developing countries, which result in easy access to opioids and chemical compounds, poisoning by such agents is also expected. Toxicological tests indicated the high prevalence of methadone and morphine, in line with the results of Afzali et al. [8], which reported the high consumption of such components in Khorazan Razavi province, Iran.

The current study faced some limitations; for example, occupational status, level of education, type of consumption, and the duration of hospitalization were not recorded; the 2 latter factors may significantly contribute to the identification of cause of death.

\section{Conclusion}

According to high mortality rate due to opium poisoning, training about dangers of opioids from the media is necessary. Physicians should have sensitivities, facing patients with decreased consciousness to recognition opioid overdose.

\section{Acknowledgment}

The authors are grateful to the manager and staff of the poisoning ward of Imam Reza Hospital. This study received no financial support; hence, all expenses were shouldered by the corresponding author.

\section{Ethics Approval}

Ethics approval was obtained from the Ethics Committee in research of Mashhad University of Medical Sciences, Mashhad, Iran.

\section{Author Contributions}

All authors were involved in the study design and data collection, interpretation of the results, and editing for intellectual content. All authors approved the final version of the manuscript.

\section{References}

1. Konradsen F, van der Hoek W, Gunnell D, Eddleston M (2005) Missing deaths from pesticide self-poisoning at the IFCS Forum IV. Bull World Health Organ 83: 157-158.

2. Eddleston M, Phillips MR (2004) Self poisoning with pesticides. BMJ 328: 42-44.

3. Repetto MR (1997) Epidemiology of poisoning due to pharmaceutical products, Poison Control Centre, Seville, Spain. Eur J Epidemiol 13: 353356.

4. Moghadamnia AA, Abdollahi M (2002) An epidemiologic study of poisoning in northern Islamic Republic of Iran. East Mediterr Health J 8: 88-94.

5. Shadnia S, Esmaily H, Sasanian G, Pajoumand A, Hassanian-Moghaddam H, et al. (2007) Pattern of acute poisoning in Tehran-Iran in 2003. Hum Exp Toxicol 26: 753-756.

6. Vatandoost H, Mirakbari SM (2002) Study of Poisoning in Adults At Poison Control Center, Loqman-E Hakeem Hospital Tehran-Iran From April 25, 2000 To April 25, 2001. The Internet Journal of Toxicology 1: 1-5.

7. Gunnell D, Eddleston M (2003) Suicide by intentional ingestion of pesticides: a continuing tragedy in developing countries. Int J Epidemiol 32: 902-909.

8. Afzali S, Kashani KM, Kolsoum FA (2008) Pattern of Mortality Due to Poisoning by Drugs and Chemical Agents in Hamadan, Iran, 2005-2007. Qom Univ Med Sci J 2: 27-32.

9. Torkashvand F, Sheikh Fathollahi M, Shamsi S, Kamali M, Rezaeian M (2015) Evaluating the Pattern of Acute Poisoning in Cases Referred to the Emergency Department of Ali-ebn Abi Taleb Hospital of Rafsanjan from October 2013 to September 2014. Journal of Rafsanjan University of Medical Sciences 14: 311-324.

10. Lotrakul M (2005) Suicide in the north of Thailand. J Med Assoc Thai 88: 944-948.

11. Ellenhorn MJ, Barcelloux DG (1988) Medical Toxicology: diagnosis and treatment of human poisoning. Elsevier, New York, USA.

12. Gossel TA, Bricker JD (1994) Toxicology in perspective. In: Principles of Clinical Toxicology, ( $3^{\text {rd }}$ edn). Raven Press, Ltd, New York, USA.

13. Afshari R, Majdzadeh R, Balali-Mood M (2004) Pattern of acute poisonings in Mashhad, Iran 1993-2000. J Toxicol Clin Toxicol 42: 965-975.

14. Güloglu C, Kara IH (2005) Acute poisoning cases admitted to a university hospital emergency department in Diyarbakir, Turkey. Hum Exp Toxicol 24: 49-54.

15. Srivastava A, Peshin SS, Kaleekal T, Gupta SK (2005) An epidemiological study of poisoning cases reported to the National Poisons Information Centre, All India Institute of Medical Sciences, New Delhi. Hum Exp Toxicol 24: 279-285.

16. Shah R, Uren Z, Baker A, Majeed A (2001) Trends in deaths from drug overdose and poisoning in England and Wales 1993-1998. J Public Health Med 23: 242-246.

17. Islam MN, Islam N (2003) Retrospective study of 273 deaths due to poisoning at Sir Salimullah Medical College from 1988 to 1997. Leg Med (Tokyo) 5: 129-131.

18. Schaper A, Renneberg B, Desel H, Langer C (2006) Intoxication-related fatalities in northern Germany. Eur J Intern Med 17: 474-478. 
Citation: Najari F, Dadpour B, Kayal IB, Khalilzadeh M (2017) Evaluation of the Patterns of mortality due to acute Poisoning in Imam Reza Hospital, Mashhad, Iran, 2016. J Toxicol Cur Res 1: 001 .

- Page 4 of $3 \cdot$ 